\title{
What If Reality Has No Architecture?
}

\section{Introduction: The Architecture of Science Versus the Architecture of Reality}

Here is a simple picture about the relation between reality and our theories about it. The building blocks of reality are natural kinds: cats, humans, protons and electrons. A good scientific theory must latch onto these natural kinds. Such a theory would 'carve nature at its joints'. And these joint, to continue with this old and alluring metaphor, are what keep the natural kinds apart. If we have a theory that does not latch onto the natural kinds, or, that does not carve nature at its joints, we have a bad theory.

If we accept this simple picture, it is clear what scientists should do: they should discover the real architecture of reality. More precisely, they are supposed to discover natural kinds and laws that connect natural kinds. The assumption is that reality has a rich architecture and science should come up with theories that mirror this rich architecture. This simple picture about the relation between theory and reality is sometimes called 'scientific realism', but I will deliberately avoid using this label because of its notorious ambiguity. I will return to the scientific realism/antirealism debate briefly in the last section.

It is difficult to deny the appeal of this simple picture and it is even more difficult to come up with alternatives that would be even half as appealing. It seems that denying the basic assumptions of this picture would amount to endorsing views in metaphysics and in the philosophy of science that fall outside mainstream analytic philosophy, and, even more importantly, that seem to conflict with the scientific worldview.

In fact, one influential argument for the simple picture of the relation between theory and reality is that if we don't accept this picture, we are forced to deny our scientific worldview as there would be no role for science if we use an alternative metaphysical picture. In short, the

"What if Reality has No Architecture?" by Bence Nanay, The Monist, vol. 94, no. 2, pp. 181-197. Copyright (C) 2011, THE MONIST, Peru, Illinois 61354. 
argument is that science presupposes the simple picture of the relation between theory and reality according to which reality is carved at its joints by good theories.

The aim of this paper is to show that this is false: we can deny that reality is neatly segmented into natural kinds and still give a plausible view about what science is supposed to do-and the way science in fact works does not rely on the dubious metaphysical assumption that reality is segmented into natural kinds.

It is important to emphasize that I do not argue for the metaphysical picture that reality has no natural kinds. The aim of this paper is to show that there is nothing wrong with this view from a scientific (or a metaphysical) point of view. On the contrary, some actual scientific practices seem to support this view. But then we have no reason to dismiss this alternative metaphysical picture without discussion. The score is simple: either there are natural kinds or there aren't. The former view has been the default position in mainstream analytic metaphysics and philosophy of science. I want to put the latter on the table as a metaphysically and scientifically plausible alternative.

\section{Natural Kinds and Natural Properties}

My aim is to argue for the plausibility of the view that there are no natural kinds. So, before doing anything else, I need to clarify what is meant by natural kinds. But this is no easy task. Different philosophers mean very different things when they talk about natural kinds.

There are many ways of grouping entities. I could group my laptop, the declaration of human rights, and Miles Davis's first composition together and that would give us a kind of sort. But this would not be a natural kind. The entities that are grouped together in a natural kind are in some way similar to one another. Nitrogen is supposed to be a natural kind because nitrogen molecules are somehow more similar to one another than they are to other entities. Of course, what sense of similarity is at stake here is notoriously difficult to specify (see Quine 1969, the locus classicus).

Some hold that natural kinds have essences: essential properties that all and only members of natural kinds have and they do so necessarily. This raises a further question about what essential properties are supposed to be. Some say they are intrinsic, nonrelational, unchanging properties, 
but this view would leave biology, the domain of evolved entities, without natural kinds (Hull 1965). As a result, some others say that essential properties can be relational, and they can change over time (Griffiths 1999, Okasha 2002, see also Ereshefsky forthcoming, Nanay 2010 and Nanay forthcoming $\mathrm{b}$ for the discussion of this proposal).

Some others deny that it must be the case that all and only the members of a natural kind have a kind-specific essence. According to the "homeostatic property cluster theory," for example, members of a natural kind share a cluster of similar properties, but no property is necessary for membership in this kind (Boyd 1999).

Depending on which concept of natural kind we accept, the claim that there are no natural kinds would have different force. But I want to explore the possibility of there being no natural kinds, not even in the weakest sense of the term. As a result, I will outline a metaphysical picture that implies that there are no natural kinds whatsoever: neither essentialist ones, not homeostatic property clusters. More specifically, I deny that there are natural properties. And if there are no natural properties, it is difficult to see how there could be natural kinds. But what are natural properties?

David Lewis introduced the concept of natural properties in his Lewis 1983. He makes a distinction between natural and unnatural properties and claims that this distinction is an objective one (Lewis 1983; 1984; 1986). Natural properties are "an élite minority of special properties" (Lewis 1983, 346) among the plebs of abundant properties. Every predicate, regardless of how disjunctive or gerrymandered it is, expresses an abundant property. Abundant properties, as Lewis puts it, "carve reality at the joints - and everywhere else as well. If it's distinctions we want, too much structure is no better than none" (Lewis 1983, 346). So we need some other, more restricted, concept of properties, which he calls natural (or sparse) properties. Natural properties are the properties "whose sharing makes for resemblance" and also the ones with "relevant causal powers" (Lewis 1983, 347).

Naturalness, according to Lewis, comes in degrees. Some really elite properties are perfectly natural. Some others are a bit less natural, whereas the vast majority are simply unnatural. Being metallic is one example he gives for a natural but not perfectly natural property. He does not give many examples for perfectly natural properties, but the ones he gives are 
"the charges and masses of particles, also their so-called 'spins', 'colours' and "flavours"' (Lewis 1986, 60, see also Lewis 1984, 228 for a similar list).

A couple of clarifications are in order. First of all, the distinction between natural and unnatural properties is one between different property-types (as opposed to property-tokens or tropes). Second, this distinction is orthogonal to the nominalism/realism debate about properties. Lewis explicitly gives two versions of drawing this distinction between natural and unnatural properties, a nominalist and a realist one. So regardless of which picture we are drawn to, according to Lewis, we need to make a distinction between natural and unnatural universals (if we have realist leanings) or between natural and unnatural resemblance classes (if we have nominalist leanings).

Further clarifications: Natural properties are supposed to be discovered by our best scientific theories: it is science that is supposed to tell us which property-types are natural and which ones are unnatural.

I am assuming that talking about natural kinds presupposes the concept of natural properties. If natural kinds have essences: essential properties that all and only members of this kind have and do so necessarily, these essential properties had better be natural properties and not highly disjunctive gerrymandered ones. But what if we opt for a version of the homeostatic property cluster theory? Remember that according to this theory, there does not need to be one single property-type, the instantiation of which is necessary and sufficient for being a member of a natural kind. It allows for an unspecified number of properties that tend to (but does not have to) go together and that are such that all and only members of a natural kind have sufficiently many of them. This conception of natural kinds also seems to presuppose the concept of natural properties as the properties that natural kinds are supposed to be the homeostatic cluster of can only be natural properties and not highly disjunctive, gerrymandered ones. ${ }^{1}$ In short, if we can show that there are no natural properties, it seems to follow that there are no natural kinds either.

The view that there are no natural properties is not new and the very concept of natural properties has been criticized (Taylor 1993; 2004; Van Fraassen 1989; Elgin 1995; see also Goodman 1955, which could be considered to be the precursor of this view). But, again, my aim here is not to give arguments in support of this view but to point out that this view could 
give us a scientifically and metaphysically plausible picture that we have no reason to reject automatically. In the next section, I sketch a positive account of how we could think about the world without helping ourselves to natural properties. I call this account "egalitarianism" as it rejects what Lewis memorably called "an élite minority of special properties" (Lewis 1983, 346) and emphasizes that all property-types are metaphysically equal. Then in Section IV, I aim to point out that this egalitarian picture is not question begging from a scientific point of view and, in fact, it is consistent with some of our actual scientific practices.

\section{A World Without Natural Kinds}

Think of property-tokens ${ }^{2}$ as points in a property-space (see Quine 1969; Clark 2000; Nanay 2009b on the concept of property-space-Lewis himself also uses this metaphor for highlighting the difference between natural and unnatural properties in Lewis 2001, 385-86). Some pairs of property-tokens resemble each other more than others: they are closer together in this property-space. Property-types are regions in the propertyspace.

One picture about this property-space is that there is a fact of the matter about where the 'true' boundaries of the regions of this propertyspace lie: there is a fact of the matter about where one natural property-type (one universal or one resemblance class of tropes) ends and where the other begins. And there is one way of partitioning the propertyspace that cuts it at its joints: that would divide it along the lines of natural properties.

Another, alternative, picture is the following. Some pairs of propertytokens are closer together in the property-space: they resemble each other more than others. But property-types are our arbitrary ways of delineating regions of this property-space. The property-space does not have joints: it consists of a number of property-tokens, some close together, some further away from each other. Property-types are our ways of grouping these points in the property-space and the way we group property-tokens together depends on our interests. In other words, there is a fact of the matter about how similar any two property-tokens are. But there is no fact of the matter about whether a property-token belongs to a property-type (see also Nanay 2009a; 2010). 
To use an old analogy, property-tokens could be thought of as stars and property-types as constellations (Darwin 1859, 397; Cournot 1851; Goodman 1978; see Hacking 2007 for a good summary). There is a fact of the matter about the distance between any two stars, but the constellations of stars, like that Cassiopeia, are our own arbitrary groupings of some stars. As Ian Hacking says, "they are convenient for navigators but the stars are grouped together by people, not nature" (Hacking 2007, 225). Similarly, there is a fact of the matter about the degree of resemblance between any two property-tokens, but, to paraphrase Hacking, propertytypes are property-tokens 'grouped together by people, not nature'.

To use a different example, take the color spectrum. It can be partitioned into different color property-types in a number of ways. Speakers of different languages and even different individuals of the same linguistic community will do so differently (see, e.g., Hardin 1988; Tye 2006; Cohen, Hardin, and McLaughlin 2006). Again, the natural way of describing this is to say that color property-tokens exist independently of us (for simplicity, I leave aside the issues about relationalist theories of color here), but the property-type 'blue' or 'green' does not exist independently of us: they come about if we group some property-tokens together under the label of 'green' or 'blue'.

I said that property-types are our grouping of property-tokens. But couldn't we group together really distant property-tokens, if we wanted to? We could. But these groupings, that is, property-types, are supposed to serve some kind of practical purpose. We could group together stars from various distant parts of the firmament, but that would hardly be called a constellation, let alone a constellation that could serve any practical purpose.

In this picture, there is no ontological difference between properties that Lewis intends as potential examples of natural properties and gerrymandered, highly disjunctive properties. There is no fact of the matter that would tell us which property-types are sparse and which ones are merely abundant. But there is a huge practical difference between property-types (see Taylor 1993; 2004; and Goodman 1955 for similar distinctions).

To drive home this point, let us consider how Goodman's new riddle could be handled in this new egalitarian framework. Goodman famously contrasted the following two predicates: (i) being green and (ii) being grue, that is, either it was first observed before 2099 and is green or it was 
not first observed before 2099 and it is blue (Goodman 1955). The question is this: what is the difference between these two predicates. One of them is projectible, whereas the other one is not. How could we explain this difference? The standard response (again, see Lewis 1983 as an important example) is that the difference is between the properties, that is, the property-types, these two predicates express. The property of being green is a more natural property, the property of being grue is a less natural one (Lewis emphasizes that neither is perfectly natural). But then we are back with the question of what makes one property more natural than another.

How could the egalitarian framework handle the difference between green and grue? This difference, according to the egalitarian, just as for Goodman himself (see especially Goodman 1955, 95), is not an ontological one or one about the degree of naturalness of these two properties. Thus, for the egalitarian, there is no difference between the property-type of being green and the property-type of being grue as far as their metaphysics is concerned: neither property-type is natural. They are both our ways of grouping property-tokens. But there is a huge pragmatic difference between the two: the property-type of being green is a useful way of grouping property-tokens that delineate a certain region of the color property-space. The property-type of being grue, in contrast, is not a particularly useful way of grouping property-tokens. The difference between green and grue is not a metaphysical, but a purely pragmatic one.

And what is true of properties is true of kinds. If we accept egalitarianism about properties, it seems that we need to deny the special status of natural kinds. If there are no natural properties, it is difficult to see how

there can be natural kinds. To put it more precisely, if there is no fact of the matter about whether a property-token belongs to a property-type, it is difficult to see how there can be a fact of the matter about whether a particular belongs to a natural kind.

\section{Science in a World Without Natural Kinds}

Let us suppose that the egalitarian metaphysical picture I outlined in the previous section is correct. What possible role could science have in this egalitarian framework? Remember that according to the egalitarian, property-tokens exist independently of us, but property-types don't. For any two property-tokens, there is always a fact of the matter about how 
close they are in the property-space: about how similar they are. But there is no fact of the matter about what property-type they belong to.

Let us make a distinction between singular and nonsingular representations. Singular representations attribute property-tokens (to particulars). Nonsingular representations attribute property-types (to particulars or sometimes to other property-types). Here is a nonsingular representation: "Japanese cars are reliable." Here is a singular representation: "my Honda in front of my house has this shade of grey."

According to the egalitarian picture, there is always a fact of the matter about whether a singular representation is correct. But there is no fact of the matter about whether nonsingular representations are correct. Important clarification: we can and do make true and false claims about nonsingular representations. I have just made (a hopefully true) one myself when I claimed that there is no fact of the matter about whether nonsingular representations are correct. But my claim is not that there is no fact of the matter about nonsingular representations at all, but a more limited one: that there is no fact of the matter about whether nonsingular representations are correct. ${ }^{3}$

What is science supposed to do? It is supposed to look for correct singular representations. And it is also supposed to postulate propertytypes that can give us nonsingular representations with high predictive and explanatory power. These property-types do not exist independently of us: we postulate them. And these nonsingular representations cannot be correct or incorrect, but they can be useful or not so useful. I call this view 'singularist semirealism'. ${ }^{4}$

Consider Carl Hempel's famous characterization of the vocabulary of science:

The vocabulary of science has two basic functions: first, to permit an adequate description of the things and events that are the objects of scientific investigation; second, to permit the establishment of general laws or theories by means of which particular events may be explained and predicted and thus scientifically understood. (Hempel 1965, 139)

If we accept singularist semirealism, then these two 'functions' of the vocabulary of science need to be kept separate. The first function is a descriptive one: we can describe 'the things and events that are the objects of scientific investigation' correctly or incorrectly. But the second 
function is not descriptive at all: it consists of the postulation of 'general laws or theories'.

I made a positive and a negative claim. The positive claim is that science is after singular representations of the world and there is a fact of the matter about whether these singular representations are correct. And the negative claim is that science merely postulates nonsingular representations and there is no fact of the matter about whether these nonsingular representations are correct.

Of the two claims, the negative one is the harder to swallow. Scientific laws are about property-types. Is singularist semirealism then committed to saying that there is no fact of the matter about whether scientific laws are correct? The short answer is: yes. The long answer will have to wait until Section VI. But before highlighting the potentially worrying consequences of singularist semirealism, I first want to turn to some encouragement from actual scientific practice.

\section{Encouragement from Actual Scientific Practice}

I want to make a modest point in this section. Actual scientific practice is not irrelevant when trying to understand deep metaphysical questions about the architecture of reality (or the lack thereof). It is not irrelevant, but it is not a straightforward tiebreaker either. If it turns out to be the case that actual scientific practice uses something akin to the framework of singularist semirealism I outlined above, this would not give us reason to reject the standard picture about the relation between theory and reality. But it would give us reason to take the singularist semirealist picture seriously, both from a scientific and from a metaphysical point of view. And this is all I aim to establish here.

One important consideration comes from the experimental nature of much of what we know as the scientific enterprise. Experiments are done on particulars with property-tokens. No experiment is done on propertytypes. What scientists manipulate are property-tokens, not property-types (see Hacking 1983 for a thorough examination of the relevance of experiments to the scientific realism/antirealism debate). Measurement is also always the measurement of a property-token and not of a property-type. So it seems that the two main tools of actual scientific practice, experimentation and measurement, are practices involving property-tokens and not property-types. Of course, on the basis of the measurement of, or ex- 
perimentation with, property-tokens, one can postulate models or laws or general causal claims that are about property-types, but this process needs to start with the attribution of property-tokens.

Ian Hacking famously wrote that "the final arbitrator in philosophy is not how we think but what we do" (Hacking 1983, 31). This may or may not be true of philosophy in general, but it seems to be uncontroversial as a motto about science: when we are trying to determine the aim of science, we should not ask what scientists think or what they should think. We should enquire about what they do. And whatever they do is done on property-tokens. The sine qua non of science is the attribution of propertytokens. This is what makes the attribution of property-types possible to begin with. If science is to give us a reliable, or even pragmatically useful, picture of the world, it needs to start with correct representations of property-tokens. And there may or may not be a fact of the matter about whether the attribution of property-types that is based on this is correct.

But here is a more specific example from a branch of science that tends to be underrepresented in the scientific realism/antirealism debate: biology. I argued elsewhere (Nanay 2010, see also Nanay forthcoming a) that Ernst Mayr's concept of population thinking (Mayr 1959/1994), which is widely accepted among biologists and even among philosophers of biology and is supposed to capture the right way of thinking about the biological domain also presupposes a version of singularist semirealismit only talks about trait-tokens of organisms and treats trait-types as "our statistical abstractions" (Mayr 1959/1994, 326). ${ }^{5}$

\section{Some Potential Worries}

After this encouragement, we now face some serious challenge: a consequence of singularist semirealism is that there is no fact of the matter about whether scientific laws are correct. But doesn't this just show that singularist semirealism is an obviously crazy view? I don't think so.

Scientific laws are about property-types. But according to singularist semirealism, there is no fact of the matter about whether representations of property-types are correct. Property-types are our pragmatically useful ways of grouping property-tokens. Hence, it follows from singularist semirealism that there is no fact of the matter about whether scientific laws are correct. I propose that this is the right way of thinking about both 
property-types and scientific laws: it is true of both of them that they are not discovered but posited by us.

David Lewis famously said that "laws and natural properties [that is, natural property-types] get discovered together" (Lewis 1983, 368). I think that this is wrong. Rather, 'laws and natural property-types get posited by us together'. Scientific laws are not out there waiting for us to discover them. They are constructed by science. Does this make them any less respectable? I don't think so. After all, and here is where the positive claim of singularist semirealism saves the day, scientific laws are postulated on the basis of (presumably correct) singular representations of the world. Science postulates scientific laws that can cover singular representations that are held to be true. Scientific laws have no more objective existence than the property-types they are supposed to be about.

But does not the rejection of the objectivity of scientific laws bring with it all kinds of uncanny consequences? One important example: isn't causation supposed to be closely linked to the laws of nature? Again, David Lewis seems to think so: "it is fairly uncontroversial that causation involves laws" (Lewis 1983, 368). But is it? Here, we need to distinguish singular and general causal claims. Singular causal claims connect property-tokens, general causal claims connect property-types. It is indeed uncontroversial that general causal claims 'involve laws'. But why would singular causal claims involve laws?

In fact, according to singularist semirealism, there is a fact of the matter about whether singular causal claims are true (as there is always a fact of the matter about property-tokens). But there is no fact of the matter about whether general causal claims are true. The relation between singular and general causal claims is of course very complex (see Sober 1985; Hitchcock 1995; 2001). But if one holds that the real causal structure of the world is captured by singular and not by general causal claims, then singularist semirealism is not making a crazy claim at all.

However, a disturbing fact remains: few titles of articles in Nature or Science are singular claims, but many of them are general causal claims. What should singularist semirealism say about that? It is important to remember that singularist semirealism does not want to purge science from general causal claims or from property-types. Property-types, scientific laws, and general causal claims are part of science and it is 
difficult to imagine a scientific theory without them. What singularist semirealism says is that these property-types, laws, and general causal claims are postulated and not discovered. But it is one of the most important aims of science to postulate property-types that are pragmatically useful for regimenting singular facts.

In short, attributions of property-types, most notably, scientific laws, and general causal claims are part of general scientific practice. But there is no fact of the matter about whether they are true. They are pragmatically useful tools at the disposal of science to group singular facts.

\section{Conclusion: Between Scientific Realism and Antirealism}

I deliberately avoided the terminology of scientific realism when formulating the main claims of the paper, but a brief remark needs to be made about how the arguments above relate to the grand scientific realism/antirealism debate. This debate has been, and remains, quite confusing. Different philosophers interpret these labels differently and it is not even clear that there is one single debate between scientific realism and antirealism (see Newton-Smith 1978; Hacking 1983 for taxonomies).

According to a fairly general formulation of scientific realism about theories, "science aims to give us [. . . ] a literally true story of what the world is like" (Van Fraassen 1980, 8). Scientific antirealists deny this. It is easy to see some of the ambiguities of this distinction. First, what does it mean to talk about the aim of science? Science is a complex social enterprise and it is not clear how we should establish what its aim is supposed to be (see Rowbottom forthcoming, section 2 for more on how to (and how not to) formulate scientific realism in terms of the aim of science).

There are many different versions of scientific antirealism, some more controversial than others. One can accept that there is always a theory that is true of a scientific domain, but deny that we can ever have access to the truth of our actual theories (this view is sometimes referred to as epistemic antirealism). Or one could deny that there is always a theory that is true of a scientific domain. As scientific antirealism is, on the face of it, a negative claim - the denial of scientific realism - there is also a wide variety of antirealist proposals as to what the realist concept of truth should be replaced with. 
The singularist semirealist account I outlined above could be thought of as a new, intermediary position in the scientific realism/antirealism debate, which would capture some of the most important realist and some of the most important antirealist considerations. According to singularist semirealism, science aims to give us correct singular representations of the world, but it does not aim to give us correct nonsingular statements. It is half scientific realism and half scientific antirealism. It is a version of scientific realism with regards to singular representations: there is always a fact of the matter about their correctness and science aims to find correct singular representations. But it is a version of scientific antirealism with regards to nonsingular representations as it denies that there is a fact of the matter about whether they are correct.

Some will undoubtedly deny that I have any right to call my view realist or even partially realist or even semirealist. I have no intention to quarrel about terminology - that is the reason why I stayed away from the loaded terms of the scientific realism/antirealism debate. But I would like to point out that singularist semirealism has a neat response to one of the most important arguments against scientific antirealism: the 'no miracle argument' (or 'ultimate argument').

One big challenge for any scientific antirealist is to explain the success of science. This challenge is so significant that it has been referred to, somewhat dramatically, as the 'ultimate argument' against antirealism (Van Fraassen 1980, 37; Musgrave 1988). The 'ultimate argument' is very simple and its original formulation comes from Hilary Putnam (although it could be traced back to J.J.C. Smart's 'cosmic coincidence' argument (Smart 1968, 39; see also Stanford 2000, 269-70; Lyons 2003)): "The positive argument for realism is that it is the only philosophy that doesn't make the success of science a miracle" (Putnam 1975, 73). Putnam says that scientific realism is the only way to explain the success of science. Is it? Would singularist semirealism make the success of science a miracle? It certainly would not. Although there is no fact of the matter about whether the laws a scientific theory postulates are true, there is a fact of the matter about whether the singular causal claims a scientific theory makes are true. And as the laws that scientific theories postulate are supposed to be based on these (supposedly true) singular causal claims, it is not a miracle that scientific theories can make successful predictions and explanations. 
Remember that for singularist semirealism, property-types are our ways of grouping property-tokens. Some groupings are more useful from a pragmatic point of view than others: they allow us to make better predictions and explanations. And, importantly, what is supposed to be grouped by these property-types are property-tokens and there is, again, always a fact of the matter about whether a particular has a propertytoken. But if this is true, then the ultimate argument against scientific antirealism does not work in the case of singularist semirealism.

The conclusion is not that we should all abandon the traditional picture about the architecture of reality and all become singularist semirealists. The conclusion is rather that we should take singularist semirealism seriously. Unlike other ways of denying the architecture of reality, it is both scientifically and metaphysically consistent and maybe even plausible. The world without natural kinds may not be such a terrible place and science in the world without natural kinds may not be such hopeless endeavor.

University of Antwerp and University of Cambridge

Bence Nanay

\section{Notes}

1. It needs to be acknowledged that it is not logically impossible to combine the rejection of natural properties with the acceptance of natural kinds of some sort, but this strategy would not provide us with projectible natural kinds. And the consensual view is that it is a necessary condition for natural kinds that they should be projectible (see, e.g., Quine 1969).

2. Important terminological qualification: I use the term 'property-token' as a convenient label that covers both tropes and the instantiations of universals. So talk of property-tokens does not commit one to the existence of either tropes or of universals.

3. More clarifications: some nonsingular representations are correct by definition. Here is an example: particulars that instantiate the property-type red instantiate the property-type red. Here is another one: particulars that instantiate the property-type scarlet instantiate the property-type red. So a more precise formulation of my claim would be to say that there is no fact of the matter about whether not analytically correct nonsingular representations are correct. For simplicity, I will go on using the shorter formulation in what follows.

4. I called this view 'singularist semirealism' partly in order to differentiate it from Anjan Chakravartty's semirealism. Chakravartty sometimes expresses very similar views to the ones I am defending here. For example, he writes that "nature is composed of dis- 
tributions of property instances, only some of whose patterns of sociability we consider and investigate" (Chakravartty 2007, 178). But his general stance is far more realist than my singularist semirealism. Immediately before the quoted sentence, for example, he writes, "what is natural goes well beyond what is useful, convenient or interesting in everyday and scientific contexts" (ibid).

5. Another encouraging quote that could be interpreted as consistent with structuralist semirealism comes from Einstein: "Physical concepts are free creations of the human mind, and are not, however it may seem, uniquely determined by the external world. In our endeavour to understand reality, we are somewhat like a man trying to understand the mechanism of a closed watch. He sees the face and the moving hands, even hears it ticking, but he has no way of opening the case" (Einstein and Infeld 1938, 33).

\section{REFERENCES}

Ariew, A. 2008. "Population thinking," in the Oxford Handbook of Philosophy of Biology, M. Ruse, ed., Oxford: Oxford University Press, 64-86.

Boyd, R. 1999. "Homeostasis, Species and Higher Taxa," in Species: New Interdisciplinary Essays, R. Wilson, ed., Cambridge, MA: MIT Press.

Chakravartty A. 1998. "Semirealism." Studies in History and Philosophy of Science, 29: $391-408$.

- 2007. A Metaphysics for Scientific Realism: Knowing the Unobservable, Cambridge: Cambridge University Press.

Cohen, J., Hardin, C.L., and McLaughlin, B.P. 2006 "True Colors," Analysis, 66: 335-40.

Cournot, A.A. 1851. Essai sur les fondements de nos connaissances et sur les caractères de la critique philosophique, Paris: Hachette.

Darwin, Charles 1859. On the Origin of Species, Cambridge, MA: Harvard University Press.

Dupré, J. 1981. "Natural Kinds and Biological Taxa," The Philosophical Review, 90: 66-90.

Einstein, Albert and Leopold Infeld 1938. The Evolution of Physics, New York: Simon and Schuster.

Elgin, Catherine Z. 1995. "Unnatural science,” Journal of Philosophy, 92: 289-302.

Ereshefsky, M. forthcoming. "What's Wrong with the New Biological Essentialism?" Philosophy of Science

Goodman, Nelson 1951. The Structure of Appearance, Cambridge, MA: Harvard University Press.

. 1955. Fact, Fiction and Forecast, Cambridge, MA: Harvard University Press. 1978. Ways of Worldmaking, Indianapolis: Hackett.

Griffiths, P. 1999. "Squaring the Circle: Natural Kinds with Historical Essences," in Species: New Interdisciplinary Essays, R. Wilson, ed., Cambridge, MA: MIT Press.

Hacking, I. 2007. "Natural Kinds: Rosy Dawn, Scholastic Twilight," in The Philosophy of Science, Royal Institute of Philosophy Supplements Volume 61, A. O'Hear, ed., Cambridge: Cambridge University Press.

. 1983. Representing and Intervening, Cambridge: Cambridge University Press.

Hardin, C.L. 1988. Color for Philosophers: Unweaving the Rainbow, Indianapolis: Hackett. 
Hempel, Carl. 1965. "Fundamentals of Taxonomy," in his Aspects of Scientific Explanation, New York: The Free Press.

Hitchcock, C. 1995. "The Mishap at Reichenbach Fall: Singular vs. General Causation," Philosophical Studies, 78: 257-91.

—. 2001. "Causal Generalizations and Good Advice," The Monist, 84: 222-46.

Hull, D. 1965. "The Effect of Essentialism on Taxonomy: 2000 Years of Stasis," British Journal for the Philosophy of Science, 15: 314-26; 16: 1-18.

Lewis, David 1983. "New work for a theory of universals," Australasian Journal of Philosophy, 61: 343-77.

—. 1984. "Putnam's Paradox," Australasian Journal of Philosophy, 62: 221-36.

1986. On the Plurality of Worlds, Oxford: Blackwell.

2001. "Redefining 'intrinsic'," Philosophy and Phenomenological Research, 63: 381-98.

Lyons, Timothy D. 2003. "Explaining the Success of a Scientific Theory," Philosophy of Science, 70: 891-901.

Mayr, Ernst 1959/1994. "Typological versus Population Thinking," in Evolution and Anthropology, B.J. Meggers, ed., Washington: The Anthropological Society of America, 409-12. Reprinted in Conceptual Issues in Evolutionary Biology, Elliott Sober, ed., Cambridge, MA: The MIT Press, 1994, 325-28.

. 1963. Animal Species and Evolution, Cambridge, MA: Harvard University Press. . 1996. "What is a Species, and What is Not?" Philosophy of Science, 63: 262-77.

Musgrave, Alan 1988. "The Ultimate Argument," in Relativism and Realism in Science, Robert Nola, ed., Dordrecht: Kluwer, 229-52.

Nanay, Bence 2009a. "The Properties of Singular Causation," The Monist, 92: 113-35. . 2009b. "Imagining, Recognizing and Discriminating: Reconsidering the Ability Hypothesis," Philosophy and Phenomenological Research, 79: 699-717.

. 2010. "Population Thinking as Trope Nominalism," Synthese, 177: 91-109. - forthcoming a. "A Modal Theory of Function," Journal of Philosophy.

- forthcoming b. "Three Ways of Resisting Essentialism about Natural Kinds," in Carving Nature at its Joints. Topics in Contemporary Philosophy, Vol. 8., J.K. Campbell, M. O'Rourke, and M.H. Slater, eds., Cambridge, MA: MIT Press, in press.

Newton-Smith, W. 1978. "The Underdetermination of Theory by Data," Proceedings of the Aristotelian Society, supplementary volume 52: 71-91.

Quine, W.V. 1969. "Natural Kinds" in his Ontological Relativity and Other Essays, New York: Columbia University Press, 114-38.

Rowbottom, Darrell forthcoming. "Evolutionary Epistemology and the Aim of Science," Australasian Journal of Philosophy.

Smart, J.J.C. 1968. Between Science and Philosophy, New York: Random House.

Sober, Elliott 1985. "Two Concepts of Cause," in PSA 1984: Vol. 2, Asquith, P. and Kitcher, P., eds., East Lansing: Philosophy of Science Association, 405-24.

. 1980. "Evolution, Population Thinking, and Essentialism," Philosophy of Science, 47: 350-83.

Stanford, P. Kyle 2000. "An Antirealist Explanation of the Success of Science," Philosophy of Science, 67: 266-84.

Taylor, Barry 1993. "On Natural Properties in Metaphysics," Mind, 102: 81-100.

. 2004. "Transworld Similarity and Transworld Belief," Australasian Journal of Philosophy, 
http://www.informaworld.com/smpp/title $\sim \mathrm{db}=$ all $\sim$ content $=\mathrm{t} 713659165 \sim \mathrm{tab}=\mathrm{issuesli}$ st $\sim$ branches $=82-\mathrm{v} 8282: 213-25$.

Tye, M. 2006. "The Puzzle of True Blue," Analysis, 66 (291): 173-78.

Van Fraassen, Bas 1980. The Scientific Image, Oxford: Oxford University Press. . 1989. Laws and Symmetry, Oxford: Clarendon Press. 